\title{
Automobile Demand, Model CyCle And Age Effects ${ }^{1}$
}

\author{
María José Moral \\ $\mathrm{UNED}^{2}$
}

and

\author{
Jordi Jaumandreu \\ Universidad Carlos III de Madrid ${ }^{3}$
}

March 2006

\begin{abstract}
This paper is aimed at exploring the existence of typical patterns of automobile model life and the formal test for age effects in a discrete-choice demand framework estimated with data on the models sold in the Spanish market. Estimates show that the evolution of market shares entails and quantifies age effects resulting from consumer demand. These effects are clearly distinguishable from the impacts generated by changes in attributes and firm pricing. They carry an exogenous factor that is full of implications for firm behavior over the life of a model: the modification of demand price sensitivities. As a result, for example, equilibrium own-price elasticities are observed to decrease until the fourth year of a model life, and then to increase again.
\end{abstract}

JEL Classification: D43

Keywords: model life cycle, automobile demand, discrete-choice, differentiated products.

\footnotetext{
We are grateful to A. Aizcorbe, M. Arellano, R. Carrasco, M. Delgado, J.C. Fariñas, A.E. Hall, J.A. Máñez, P. Marín, A. Pakes, C. Pazó, L. Robles and M. Waterson for useful comments and suggestions. We also wish to thank the audiences at many seminars and the ASSA meetings (Boston, 2006). This research has been partially funded by the projects CICYT SEJ2005-07913, SEJ2004-02525, SEC97-1368, DGI SEC2000-0268 and PGIDIET03PXIC30004PN. The usual disclaimer applies.

2 Universidad Nacional de Educación a Distancia, Dpto. de Economía Aplicada e $\mathrm{H}^{\mathrm{a}}$ Económica, Senda del Rey 11, 28040 Madrid (Spain). Tel.: 3491 3988930, e-mail: mjmoral@,cee.uned.es

${ }^{3}$ Dpto. de Economía, Madrid 126, 28903 Getafe (Spain). Tel.: 3491 6249863,e-mail: jordij@eco.uc3m.es
} 


\section{Introduction}

Car model turnover is an important characteristic of the automobile market. The entry of new models and the exit of others over time are quantitatively important. Moreover, the exit of a model and the entry of another are often the two sides of a unique operation synchronized by their manufacturer. Hence there exist life cycles of models. Some are short, others longer. The life of extremely successful models is boosted by producers at certain moments in time with changes in the current version, but old models are often simply replaced by new ones.

The life cycles of models must be seen as the result of the interaction between consumers' preferences and producers' decisions, but consumers' demand evolution is likely to play a crucial role. The presence of defined patterns of demand associated with model age (the time that a model has been marketed) suggests a likely explanation for market shares evolution over time. And consumers' age-related behaviour is likely to impact the price sensitivity of demand with respect to the own-price of models and to the prices of competitor models. As long as firms react to these changes, the resulting equilibrium elasticities are, of course, endogenously determined, but the evolution of consumer demand carries an important non-controlled factor of modification by the firm, given the remaining factors.

The purpose of this paper is to explore the effects of the age of a model on automobile demand, both descriptively and using techniques of the discrete-choice approach to market demand estimation. In particular, we begin by looking at the characteristics of the life cycle of models by means of a non-parametric description of the relationships between model shares and model ages. Then we specify and test for the presence of age effects on the demand for models using the discrete-choice framework (see Berry (1994), and Berry, Levinsohn and Pakes (1995) -hereafter BLPfor a paramount application to the automobile market. ${ }^{1}$ )

Consumer demand change with model age is likely to have important consequences for firm behavior. Firstly, firms are likely to respond to these changes in the short run with (optimal) pricing adjustments. Secondly, firms are likely to carry out minor model changes in order to try to enhance the durability of the models. Thirdly, 
firms will adopt the exit-entry decisions of their models according to the impact of these changes on profits. The entry decisions of models are associated with large sunk costs (design, plant adaptation, launch,...), and both the decisions of new entry as well as the replacement of a model by another (cannibalisation) will be adopted only when the evolution of demand makes this change profitable. All this makes the study of the age effects on demand an interesting step previous to undertaking more complete specifications of the forces underlying product decisions.

This study relies on a constructed panel data set for the Spanish car market, a particularly useful tool for studying model dynamics. Over the seven years 1990-96, we observe the monthly registrations (sales) of a total of 182 models, which account for virtually the entire market and are subject to a high turnover. The data have been elaborated and matched to a database on prices and technical characteristics.

Results clearly show that car models have life cycles. Firstly, shares tend to increase until the course of the fourth year in the life of a model. Secondly, shares subsequently tend to decrease as time goes by, and this deterioration may account for, on average, one third of its value. Thirdly, shares of surviving models tend to be higher, denoting that firms decide to discontinue the models with the worst evolution. On the other hand, we highlight the fact that demand age effects exist and are important in explaining shares patterns: once model attributes, exogenous time demand determinants and price effects are accounted for, age explains a significant part of the evolution of shares. In addition, equilibrium elasticities betray the impact of model age: average elasticities decrease during the three first years of model life and increase afterwards.

The rest of the paper is organized as follows. Section Two discusses the possible meaning of age effects in more detail and briefly relates this study to other empirical findings. Section Three introduces the data. Section Four is devoted to a description of the models of life cycles by means of non-parametric analysis. Section Five explains the specification of age effects in a discrete choice framework, and Section Six presents the estimation and results. Finally, Section Seven concludes. A data appendix gives some details on the sample and variables. 


\section{Age effects}

Consumer demand evolution presumably has an important role in the life cycles of models. ${ }^{2}$ In fact, there seem to be defined patterns of demand associated with model age, i.e., how long the car model stays on the market. Shares, as a matter of fact, tend to change over time much more pronouncedly than what can be explained by observed relative model attributes.

One possible explanation is that consumers also valuate the degree to which new models possess disembodied attributes like "newness" or "latest design," and old models possess "prestige" or "good reputation," all of them attributes that change with age. It may be that consumers simply like a series of minor embodied but unobservable technical features included in the newest models and judge them to be incorporated (or not) in enduring models. If this were the case, the explanation for the evolution of market shares over time would be the evolution of average valuation with model age.

Most marketing literature on product life cycle, however, uses the alternative "adoption" approach. The path of sales over product age would be explained by the long-term purchasing behaviour of some consumers who act as "innovators" while others behave as "imitators." See Kwoka (1996) for an application of this approach to the life cycle of minivans. But even if consumers do not differ in their time readiness to buy newly introduced models, the choice sets of consumers may be changing as information about the new models spreads. See Goeree (2005) for an application of the impact of advertising on the enlargement of the choice set of consumers in the computer market.

In practice, it seems difficult to disentangle these two explanations that probably operate at the same time. And, in fact, it seems perfectly possible to test for the presence of time effects and remain uncertain about the precise origin of them. We are going to add the time effects to the usual linear utility specification. In the first case, one can interpret the age effects as reflecting the evolution of the average valuation of consumers. In the second case, one can take the age effects as a simple reduced form specification for the shift of the relevant distribution of consumers over time. 
The effects of model age through changes of demand can be examined by studying their impact on the elasticity of demand with respect to the own-price of the model (and on the cross-price elasticities, i.e., the elasticities with respect to the prices of competing models.) As long as firms react optimally to the changes in demand, price elasticities are, of course, variables endogenously determined in equilibrium. They also depend on the firms' decisions on prices, changing attributes and introducing models. But equilibrium elasticities are an important tool for description and analysis (e.g., in the study of mark-ups), and hence the impact of age on (equilibrium) elasticities is worthy of assessment even in the absence of a structural model to separate all the effects.

In that sense, changes in price elasticities can help to understand different phenomena that arise in these markets. For example, if a multiproduct firm faces ownprice product sensitivities whose absolute value increases over time (and parallel exposure to rival price competition) it is likely to revise its product mix accordingly. It may be in the firm's interest to eventually substitute new products for the oldest ones in order to preserve the maximisation of the expected profitability of the product mix that it sells. In the long run, the evolution of elasticities and the effect of age are likely to be linked to all product decisions, from model improvements ${ }^{3}$ to entry/exit decisions.

Only a few papers have directly addressed the life cycle of products introduced by multiproduct firms in a differentiated product industry, and most of these papers have been devoted to industries experiencing a high product turnover derived from an intense process of innovations. Bresnahan, Stern and Trajtemberg's (1997) is perhaps the closest to our setting. Working within a discrete choice demand framework, they study how two disembodied attributes of IBM-compatible personal computers (being a "frontier" product, being branded) impact demand elasticities and hence temporary market power, finding a role for these two sources of differentiation. Davis (2006), which also uses a discrete-choice demand model, introduces a time effect (weeks that a film is at a theater) as a characteristic. Other studies have instead focused directly on the description of the entry and exit process, trying to assess determinants and choices. Among them, Stavins (1995) describes the positioning in the attributes' space and the probabilities of exit in personal computers, and Greenstein and Wade (1998) the product 
introduction determinants and hazard rates of mainframes. An important exception to the highly changing technological setting is Asplund and Sandin (1999), who study the Swedish beer market during the 1990s, a market also characterised by a rapid product turnover. Studying hazard rates, they find patterns of product life and turnover that are very similar to the ones we obtain in our demand framework.

\section{Car model turnover in the Spanish market}

This section briefly discusses the data and then characterises model turnover during the 1990s in the Spanish car market.

Car producers distinguish models, characterised by a model name, from the versions of these models, which they present as slight variations in the characteristics of the model. Our data set takes models, just as they have been defined by producers, as the elemental units of analysis (see below for a detailed justification). The basic data consists of the breakdown of monthly new car registrations (sales) by models from January 1990 to December 1996 (an entry occurs when a new models appears.) A total of 182 models is covered (see Data Appendix).

The information gathered for each model includes price (list retail price), attributes (for the attribute variables used in this paper, see Table A.1) and the variable that is crucial to our analysis: age. This variable measures in months how long, at time $t$, a model has been on the Spanish automobile market.

We group models into 5 categories that closely resemble common industry and marketing classifications. The classes considered are: small, compact, intermediate, luxury and minivan. For some purposes, we will also distinguish between the small "mini" or city cars, and the small "domestic" cars, the very popular, somewhat superior models produced domestically. The number of models in each segment is, respectively, 33, 37, 56, 47 and 9. "We will distinguish between "domestic" and "foreign" cars, by employing standard demand (not supply) criteria. We will call "domestic" the models sold by the brands which have domestic production, neglecting the fact that some of them are really produced abroad and imported. There are 7 big (export-oriented) multinational manufacturers that produce domestically, but whose domestic output is 
subject to complex transnational decisions about how to allocate the production of the models geographically. ${ }^{5}$ We will call "foreign" the cars sold by the firms without any domestic production. Grouping together the models manufactured by the same producer gives a total of 31 firms or brands, 7 with domestic production and 24 foreign producers.

Models seem to be a basic product category, both for demand and supply reasons. On the one hand, models have a name and an image, and firms invest heavily in advertising their models. This implies that consumers basically choose among models, and that firms incur some demand-rooted sunk costs in launching models. On the other hand, models also have some basic attributes that remain fairly stable over time. As Table 1 illustrates, for our 182-model sample, these attributes seem to be related mainly to size and power characteristics. This strongly suggests that model launching also implies technology-related sunk costs (design, manufacturing facilities adaptation, etc.). Demand and cost side sunk costs provide a rationale for firms to stay with their living models. In fact, life spans are, as we will see below, heterogeneous, and they can be spotted by minor modifications in model characteristics. Producers try to boost the life of models at certain moments with small changes. ${ }^{6}$

The ideal data for the exercise we want to perform are data with strong entry and exit of models. The Spanish car market of that time meets this requirement, as shown in Tables 2 and 3. There is an important increase in the number of marketed models (36\%) and a rather high rate of model turnover $(20 \%)$. The evolution of the market over our sample period shows two other important facts (see Table 2): some significant demand variability and a fall in tariffs, perfectly foreseeable years earlier, followed by the corresponding increase in foreign car penetration. There was an important demand downturn in 1993 and, to a lesser extent, in 1995 (and also a fall in prices), and in 1990, 1991 and 1992, the tariffs for EEC imports and non-EEC countries were gradually reduced. ${ }^{7}$ As a result, the share of domestic models tends to fall as of 1992, while the share of foreign models increases (from $18 \%$ to almost $25 \%$ ).

Let us concentrate on model increase and turnover. Table 2 reports an important increase in the number of models marketed (36\%) and the corresponding fall in sales 
per model, given the detrended demand. The net entry of models is especially important in the first half of the period, but continues until the end. Table 3 details gross entry and exit and the age distribution evolution. As can be seen in the last two rows, a high, rather stable yearly rate of turnover underlies net entry (entry+exit over the existing models is about $20 \%{ }^{8}$ ) As a result, only one fourth of the models marketed by 1997 are models that were already on the market at the beginning of the 1990s.

However, the market context implies that the study of model turnover must be carried out in a situation of increasing product competition interwoven with a market opening (which probably triggered the new competitive intensity.) Accordingly, some remarks are pertinent. Firstly, it must be noted that the increase in the number of products is mainly an endogenous outcome generated by all the participants. For example, Asian producers account for a somewhat disproportionate share of gross (and net) entry of models, but all firms contribute to the increase in the number of models. ${ }^{9}$ Secondly, most of the product entry and exits come from the decisions to replace one model with another. Table 4, which reports all the entries and exits of the models, depicts the firms' entry-exit pairs that are only separated by one or, at most, two years' delay. These pairs amount to more than $90 \%$ of the number of exits. Given these two characteristics, increased competition seems to have influenced the pace of model introduction more than changed its form. In principle, this justifies treating all the models symmetrically.

\section{Exploring model life cycle}

The data set provides us with extensive information on the different phases of the life of models. We observe the entry of models, the market evolution of models that have been marketed for different time intervals, and exit. In this section, we focus on the simple description of the evolution of market shares over model ages to detect and characterise average properties of the life cycle of models. To do this, we will employ non-parametric regression techniques.

Let $s$ be the market share of a model at a given moment in time (we drop model and time subindices for simplicity), and let $\tau$ be its age or time elapsed from the 
moment that it was released on the market. Our first aim is to describe model shares as a function of model age, that is, the expectation of model shares conditional on $\tau$, $E(s \mid \tau)$.

For each model/month in the sample, we have a market share value that is associated with the age of the model, which gives a total of 9,251 non-zero share-age observations. Moreover, for each model that exits the sample before December 1996, we complete its sample observations with the assignment of a zero market share until reaching the maximum age that we will consider $(180+84=264$ months. $)$ This is all we observe, because we have two types of censoring. For the non-exiting models, we cannot observe their shares from their last observation onwards (right censoring). We also cannot observe the early life observations of the models; which were already on the market by January 1990 (left censoring). To perform our descriptive exercises, we will pool together all the non-censored (positive and zero) observations, which gives a total of 19,528 observations. Interestingly enough, the density of these observations is rather uniform throughout the ages considered (see Figure A.1)

The conditional expectation of $s$ may be written by the law of iterated expectations as

$$
\begin{aligned}
E(s \mid \tau) & =P(s>0) E(s \mid \tau, s>0)+P(s=0) E(s \mid \tau, s=0) \\
& =P(s>0) E(s \mid \tau, s>0)
\end{aligned}
$$

where the second equation follows from $E(s \mid \tau, s=0)=0$. This expression shows that the expected share is the result of two factors: the probability of still being on the market for each age, or probability of survival, and the expected share conditional on age and survival. Therefore, to decompose and interpret the expectation of $s$ conditional on age, we will also estimate and study the survival function $P(s>0 \mid \tau)$ and the expectation of $s$ conditional on age and survival $E(s \mid \tau, s>0)$.

We non-parametrically estimate $E(s \mid \tau)$ and $E(s \mid \tau, s>0)$ by means of the simple Nadaraya-Watson estimator (see, for example, Wand and Jones, 1995), using the entire sample and the subsample of positive shares, respectively. To estimate the 
survival function, we compute the ratios at each $\tau$ of the number of models with positive shares to the total number of observations for this age (see Kiefer, 1988).

Figure 1 shows the result of estimating the expectation of $s$ conditional on age. Figure 2 depicts the results of estimating the two components according to expression (1) of this expectation. Panel $a$ of Figure 2 shows the estimation of the survival function and Panel $b$ reports the result of estimating the expectation of $s$ conditional on age and survival. Finally, the different panels of Figure 3 give the results of estimating the expectation of shares conditional on age in four car subsamples (small, compact, intermediate and luxury) of domestic and foreign models.

The curves show many things about model life cycles. Firstly, the expectation of $s$ conditional on age shows that models invariably come out on the market with relatively high sales, probably due to the advertising campaigns that precede their entry. However, for most models, it takes some time to reach the maximum market share. This time seems to range between 24 and 48 months (shares peak over the course of the third and fourth years), though it is clearly less for foreign cars.

Secondly, according to the survival function, the probability of leaving the market before the first 24 months is negligible, and only $10 \%$ of the models exit before the first 48 months. But $50 \%$ of the models have disappeared from the market by the end of the eighth year, and $75 \%$ by the completion of the twelfth.

Thirdly, the survival function shows that the probability of leaving the market increases steadily from the fourth to the twelfth years, while the expected share conditional on age and survival tends to increase during the same period: the average share of the surviving models tends to be somewhat higher. This shows that exit particularly affects shares under the average size and/or poor growth perspectives.

Fourthly, the small fraction of models that reaches the age of twelve years can still endure longer, maintaining high relative shares.

As far as the differences between domestic and foreign cars are concerned, there are two main points that are worthy of comment. First of all, the sharpest contrast is 
between the shares reached by the domestic models and the smaller shares reached by foreign models. Secondly, smaller domestic cars and bigger foreign cars tend to last longer on the market than their respective counterparts.

This simple description of average model life cycles does not pretend to determine the different forces at work and, in particular, whether there is any role for the age of the model separate from the role of the observed model attributes and their evolution over time. However, the reported evidence reveals strong share evolution patterns that suggest a positive answer. The following sections are devoted to the specification and estimation of age effects in an explicit demand framework to confirm this hypothesis.

\section{The demand for models over time}

Discrete-choice demand models seem to be the natural context in which to introduce and investigate changes in consumer demand over time (see the references in the introduction). These models build up the demand equations based on explicit links between product market shares and the framework of consumer utility. Furthermore, the standard model employed can be easily enlarged to account for these types of changes. Let us explain our specification.

The discrete choice approach obtains the demand equations by relating observed market shares with the shares predicted by the utility framework. Following Berry (1994), and employing the standard linear utility specification, a demand equation for model $j$ can be written relating a non-linear transformation of the vector of observed market shares $s$ to the average utility level for model $j$ as

$$
\delta_{j}(s)=\bar{\delta}_{j}\left(x_{j}, p_{j}, \widetilde{\xi}_{j}\right)=x_{j} \beta-\alpha p_{j}+\widetilde{\xi}_{j}
$$

where $p_{j}$ is the price of the model, $x_{j}$ is the vector of observed product characteristics, and $\xi_{j}$ represents the effect of product characteristics unobserved by the econometrician on utility. In particular, if consumer utility is assumed to be 
$u_{i j}=\bar{\delta}_{j}\left(x_{j}, p_{j}, \widetilde{\xi}_{j}\right)+\varepsilon_{i j}$, with $\varepsilon_{i j}$ identically and independently distributed over products and consumers with the extreme value distribution, the market share equals the probability of a logit model. Then $\delta_{j}(s)$ is the simple transformation $\ln s_{j}-\ln s_{0}$, where $s_{0}$ stands for the share of the so-called outside good or the alternative of not buying any of the models, which provides a useful linear estimable model. ${ }^{10}$

In this framework, the probability of buying a particular product and hence the predicted share for this product is the probability of $u_{i j}>u_{i k}$ for all $k$. We naturally enlarge the framework by considering $\bar{\delta}_{j}\left(x_{j}, p_{j}, \widetilde{\xi}_{j}, \tau_{j}\right)$, i.e., mean choice also depends on the age of the model. As remarked in Section 2, this specification is uncertain about the origin of the effect, that is, which part comes from a change in valuation and which part from a change in the consumers concerned.

We specify $\bar{\delta}_{j}\left(x_{j}, p_{j}, \widetilde{\xi}_{j}, \tau_{j}\right)$ including two possible consumer utility effects of model age. Firstly, we include a direct effect. The standard specification (2) already uses $\xi_{j}$ as disturbances to account for unobserved factors. Our specification can be simply seen as splitting the unobserved utility effects into three components: $\xi\left(\tau_{j}\right)$, the time-varying effect of unobserved attributes measured through the impact of model age; $\xi_{j}$, a time-invariant component related to stable, unobservable characteristics of the model; and $\xi_{j t}$, the remaining time-varying unobserved effects on the utility of model $j$.

Secondly, we will include an additional possible age effect through the marginal utility of income $\alpha$. Parameter $\alpha$ may be argued to reflect the different marginal utilities associated with buying models with different degrees of penetration in the market, perhaps of the average consumer or perhaps of different consumer distributions. To test for these age effects, we will specify the marginal utility of income as $\alpha+\alpha\left(\tau_{j}\right)$.

The simplest logit specification imposes strong constraints on the pattern of substitution among goods, but several model extensions have been developed in order to relax these constraints. The constraints follow from the exclusive additive specification of consumer heterogeneity. BLP-type model specifications reinforce heterogeneity 
through random attribute and price coefficients. One sensible alternative which relaxes constraints by incurring lower computational costs are nested logit models, where alternatives are grouped using a-priori information. ${ }^{11}$ In this study, we combine coefficients varying across segments, which we will write as $\alpha_{g}$, with a nested logittype estimation, by including segment-specific dummies in order to pick up the segment effects $\eta_{g} \cdot{ }^{12}$ It turns out to be a simple, theoretically suitable specification when income effects are expected and, in practice, gives sensible demand elasticity estimates. $^{13}$

Allowing for a time subscript, the enlarged logit specification can be written as

$$
\ln s_{j t}-\ln s_{0 t}=x_{j t} \beta^{*}-\left(\alpha_{g}^{*}+\alpha^{*}\left(\tau_{j}\right)\right) p_{j t}+\eta_{g}^{*}+\xi^{*}\left(\tau_{j}\right)+\xi_{j}+\xi_{j t}
$$

where asterisks indicate that the corresponding coefficients must be understood to be scaled by the factor $(1-\sigma)$. Equation (3) can be estimated subject to the constraint that the coefficients of segment dummies add up to zero, giving an estimate of the effects up to a constant. Then mean utilities can be estimated up to a constant (and hence "inclusive values" up to a multiplicative factor), and $\sigma$ can be obtained in a second step by means of an auxiliary regression. ${ }^{14}$ Relationship (3) is the equation that we estimate in the next section.

\section{Econometric estimation and results}

\subsection{Estimation strategy}

As it is well known, one of the main problems to be solved in the specification and estimation of demand equations is the treatment of the endogeneity of prices. In addition, our data consist of unbalanced panel observations for a rather standard number of individuals (182 models) but with a more unusual data frequency: monthly during a seven-year period. This entails some advantages to estimating the parameters of interest, but also the need for specific methods to address some estimation problems: the heterogeneity of the time information content ( $\mathrm{T}$ is large, but only with respect to the 
frequency of change of some variables), and the serial correlation of the disturbances. In what follows, we briefly explain our estimation choices.

Prices are likely to be correlated with the $\xi_{j}$ and $\xi_{j t}$ components of the disturbance (the time-invariant impact of unobserved model characteristics and the shocks.) In the first case, this happens because there are presumably many unobserved characteristics that go into determining the marginal cost of the models, and hence their prices, which simultaneously influence consumer utility. In the second case, it occurs because prices are determined at the same time as consumer demand, and both variables are likely to be influenced by common market shocks. ${ }^{15}$ Accordingly, we will use as instruments, in a GMM framework, the differences of the prices with respect to their individual time means, $\tilde{p}_{j t}=p_{j t}-(1 / T) \sum_{s} p_{j s}$, lagged a number of periods. This is likely to pick up just the time variations of prices (and not over models), and only those which occur prior to the contemporaneous market events. ${ }^{16,17}$ To test the validity of the instruments employed, we will use the Sargan test statistic of the overidentifying restrictions.

Individual effects and short-term movements will induce autocorrelated errors. To obtain inferences robust to serial correlation, we will need to use a robust estimate of the variance-covariance matrix. To obtain such an estimate, we will use an average over individuals of Newey-West-type computations of the individual autocovariances that take advantage of the size of T (see Newey and West (1987)).

\subsection{Econometric specification and estimation}

The dependent variable consists of the (log of the) monthly share observations of the models minus the (log of the) monthly shares of the outside good. Both shares are computed by taking the current number of households as the market size. ${ }^{18}$ Among the explanatory variables, we can distinguish three groups: control variables, model

attributes and price, and variables aimed at picking up the age effects. To control for seasonality and unspecified time effects (for example, the fall in demand), we include a 
set of monthly dummies and another of yearly time dummies, respectively. Let us detail the second and the third group of variables.

We employ the following attributes: measure of power, the cubic centimetres to weight ratio $(\mathrm{CC} /$ Weight $)$; fuel efficiency, the $\mathrm{km}$ to litre ratio $(\mathrm{Km} / \mathrm{l})$, measure of size and safety, length times width (Size), and the "luxury" proxy, maximum speed in $\mathrm{km} / \mathrm{h}$ (Maxspeed). The use of other characteristics or a more complete list does not change the main results. The price effects are specified for the main five segments used in the estimation: Small, Compact, Intermediate, Luxury and Minivan. We expect lower coefficients (in absolute value) the higher the segment is. When specifying the segment dummies, however, we also consider the division of small cars into two subgroups: small-mini and small-domestic.

The direct age effects are included as a third-order polynomial of the age measured in months (higher order terms turned out not to be significant.) The marginal utility effects of age are specified by including the set of dummies interacted with price and corresponding to the age intervals (in years) observed in the sample. After some experimentation, we established the 36 to 48 -month age interval as the reference interval.

Several instrument sets were tested with very similar results, invariably using price differences with respect to the individual time means with different lags. ${ }^{19}$ The reported estimate uses as instruments the sixth and twelfth lags of the (segment) price variables in differences, 20 age dummies (in years) and twenty interactions of the ages, and the twelfth lag of the variable price in differences. The number of overidentifying restrictions of our preferred estimation is hence 25 , although very similar results can be obtained with a smaller number of instruments. As we employ twelve period-lagged variables, we must discard all the individuals with twelve or fewer observations, retaining 164, and use a maximum of 72 time observations. Note that this implies that we are not able to estimate the age effects during the first year of the model life (the year 0). 
The reported coefficient estimates are one-step GMM estimates, obtained by employing the standard weighting matrix ${ }^{20}$ (the $\left(\sum_{j} Z_{j}^{\prime} Z_{j}\right)^{-1}$ consistent estimate of the

inverse of $E\left(Z_{j}^{\prime} \bar{\xi}_{j} \bar{\xi}_{j}^{\prime} Z_{j}\right)$, where $\bar{\xi}_{j}=\left(\xi_{j}+\xi_{j 1}, \ldots, \xi_{j}+\xi_{j T}\right)^{\prime}$ and $Z_{j}$ represents the set of instruments for individual $j$ ). All the statistics are then computed using the robust to heteroskedasticity and serial autocorrelation "two-step" weighting matrix. ${ }^{21}$ The reported Sargan test is also a two-step statistic.

\subsection{Results}

Table 5 presents the results of our preferred estimation. The statistics and estimated coefficients are sensible. The Sargan test confirms the validity of the instruments employed. Control variables present sensible patterns and the attributes show the expected impacts. The implications concerning the role of age are reasonable. We comment in more detail below.

Let us focus on the price effects. Table 6 reports a sample of the estimated price elasticities, ${ }^{22}$ which includes three models for each segment. Firstly, own-price elasticities of intermediate and luxury cars, preferred mostly at higher income levels, are clearly lower than the elasticities shown by the small and compact cars. Secondly, intrasegment cross-price elasticities tend to be lower the higher the segment is. Thirdly, cross-segment cross-price elasticities are significantly lower, presenting a fall that is highly influenced by a high estimated level of similarity among models inside the nests (0.84, which, notwithstanding, turns out to be a low value when compared with the $\sigma$ obtained in standard nested estimations). Cross-segment cross-prices, however, show a very defined pattern. Price changes of small-mini and luxury cars, the two extremes of the scale, have very small impacts on the demands for cars from all the other segments. Price changes of small-domestic and compact cars, however, have higher effects more or less disseminated throughout the other classes. Also, the price of intermediate cars has mainly significant impacts on the demand for luxury cars. Reading this the other way, the smallest cars are relatively good substitutes for other small and compact cars, as are luxury cars especially for the intermediate cars, while price changes of the 
smallest and luxury cars promote substitution relatively more intensely inside the segment. Everything looks as though we have a sensible estimate of price effects.

Let us now concentrate on the age effects, focussing on the first twelve years of life. First of all, the direct effect implied in Table 5 by the age polynomial is clearly significant. Additionally, marginal utility of income is also influenced by age, although to a limited extent. Only the first two price-age interaction terms before the reference interval are individually significant. That is, age influences the marginal utility of models before they reach their $36^{\text {th }}$ month on the market. All the other interaction terms individually present statistically non-significant values and show no defined pattern. The age polynomial plus the first two indirect age effects give a clear pattern of change of mean utility $\bar{\delta}_{j}\left(x_{j}, p_{j}, \widetilde{\xi}_{j}, \tau_{j}\right)$, evaluated at the median price, which is summarised in the third column of Table 7. In contrast to the non-parametric regressions of section 3, notice that here we are measuring net age impacts on shares, free of price and attribute change effects, reflecting how average consumer valuation changes with age.

The effects imply that, when a model is brought out on the market, time favours the increase of its market share. Consumers may have a high initial valuation of the attributes embodied in the new model, but they are initially reluctant to choose it when offered similar alternatives. The tendency of shares to increase with the passing of time ends, however, when the model has been marketed for three years. From this moment on, the simple age of models ceases to favour them and begins to show the opposite effect until the moment the car reaches its eighth year of life. The average market share's damage attributable to the course of time during this stage is more than one third of the share. However, models that surpass this time threshold (and remember that only $50 \%$ do), show higher market shares. Additionally, the $30 \%$ that go beyond the age of twelve years continue to show high shares for a number of years.

As a consequence of age effects, equilibrium elasticities vary with model age. Columns four to sixteen of Table 7 give segment averages of elasticities over ages, using models that fit two groups: models that survive less than seven years and models that survive between seven and thirteen years. This splitting is used to highlight the evolution of elasticities with age: as models that survive more years tend to show 
somewhat lower elasticities, putting all models together tends to blur the trends. The table shows that own-price elasticities clearly decrease steadily during the first years of a model's life. On average, own-price elasticity decreases until the fourth year of life. Moreover, elasticities tend to rise more or less steadily with the age of the model.

\section{Conclusion}

Car model turnover is an important characteristic of the automobile market. Entry, exit, and the specific entry of new models to replace old ones are quantitatively important and, in our Spanish sample as probably in most countries, have been recently increasing over time. Model life cycle is reflected in typical patterns of evolution of model market shares, hardly explainable if one only considers the evolution of their attributes and price. These patterns suggest links between consumer demand for models and their marketing age, and these links are likely to have important consequences for firm strategies, which respond to consumer and market evolution via pricing, change of attributes and, finally, model exit-entry decisions.

This paper has been aimed at exploring the existence of typical patterns of model life and the formal specification and test for age effects in a framework of demand for car models. We have used a suitable data set which includes detailed model sales over time, in addition to information on model attributes, price and age, in a period of high entry and exit. Age effects have been specified by enlarging the discrete-choice approach to the estimation of market demands to explain the evolution of market shares. Estimations have shown that the evolution of shares includes age effects which are clearly distinguishable from the impacts generated by changes in attributes and firm

pricing. The impact of attributes and prices has been estimated well enough to ensure the reliability of the conclusions on age effects.

Our study has shown that, ceteris paribus, shares of models tend to increase the three first years they are marketed and then begin to deteriorate as time goes by. Firms can boost model presence on the market with different version improvements and, if a model survives, its reputation is likely to give new inertia to shares at later stages. However, age effects carry an exogenous factor of modification of the relevant model 
elasticities, to which firms must react with their pricing and product strategies. Average elasticities betray these age effects, first decreasing and then increasing. The full understanding of age effects and the interaction of age with firm strategies deserve further research. The testing and specification of age effects must be considered a first step towards the development of structural models for product decisions. 


\section{Data Appendix}

This paper uses a constructed data set created for the analysis of the automobile market during the 1990s (details on the construction of the data set can be found in Moral, 1999.) The basic data consist of the breakdown by models of monthly new car registrations (sales). Registrations come from an administrative source, the Dirección General de Tráfico, and have been supplied by $A N F A C$. The data set has been cleaned, retaining $99 \%$ of the registrations, and has been matched to a database on prices and technical and physical characteristics of the models, collected and elaborated from a specialized review (Guía del Comprador de Coches.)

The data set takes models just as they have been defined by producers. Only super-luxury and marginal models have been dropped from the sample, and some similar models with extremely small sales have been aggregated in a single model. On the other hand, to meaningfully fix the date of exit of models, we have selected the month in which the previous six-month mobile average of unit registrations of a model falls below 10 units. This leaves a total of 182 car models, with an average of 110 models marketed per month and an average of 50 monthly observations per model.

The matching of the model sales data with model attributes has been carried out using, when possible, the characteristics of the model version with the highest sales. Unfortunately, detailed sales per version are not available for imported cars. In these cases, an intermediate version has been selected, sometimes based on incomplete information on sales of the versions.

The information gathered for each model includes prices (list retail price and manufacturer's price), power-related variables, performance characteristics, consumption, size-related variables and, finally, the presence of standard equipment and the availability of options. In addition, the variable age measures how long a model has been on the Spanish automobile market. For the models already existing at the beginning of the sample, the marketing age at the starting observation (January 1990) has been approximated with market information on external used cars and by considering a maximum of 180 months (15 years.) Table A.1 reports the content of each variable that we use in this paper. 


\section{Footnotes}

${ }^{1}$ The discrete-choice approach to demand estimation, developed for differentiated products markets, has recently been enlarged, enriched, and applied extensively to the modelling of several markets, in particular to the automobile market. Bresnahan's (1987) automobile article can be considered a precedent of this type of model. Goldberg (1995), Feenstra and Levinsohn (1995), Verboven (1996), Berry, Levinsohn and Pakes (1999, 2004), Goldberg and Verboven (2001) and Petrin (2002) include automobile demand estimations related to the discrete-choice method.

2 In general, demand change and technological progress interact in raising product life cycles (for a general presentation of cycles, mainly at the industry level, see Klepper (1996)). However, product cycles present many industry-idiosyncratic characteristics.

${ }^{3}$ Management literature stresses the importance of adopting techniques to enhance the durability of products.

${ }^{4}$ This classification is close to those used by Verboven (1996) for European cars (mini and small, medium, large, executive, luxury and sports), and Goldberg (1995) for the American car market (subcompact, compact, intermediate, standard, luxury and sports.) The main differences are the aggregation of luxury and sports cars in a single class, and the specification of a class for minivans.

${ }^{5}$ Citroen, Ford, Opel, Peugeot, Renault, Seat and Volkswagen.

${ }^{6}$ BLP define models in their twenty-year US sample by requiring, in addition to the same name, that the width, length, horsepower or wheelbase do not change by more than ten percent. Comparing our data with BLP data, it turns out that we observe more or less the same cross-sectional average number of models (110 vs. 118), but also that a model lasts on average 4.2 years, while they observe a model lasting only 2.2 years. Of course, our definition of model is not the same (we only rely on the name) but, from Table 1 , it can be verified that the adoption of similar criteria to BLP would have a small effect (in fact it would only reduce our average number of years from 4.2 to 3.3). This seems to say that our turnover level is not so high by US standards.

7 The tariffs for the EEC imports were gradually reduced to $13.1 \%, 8.7 \%$ and $4.4 \%$, disappearing the following year. The tariffs for the non-EEC countries were reduced during the same years to $23.1 \%$, $18.8 \%$ and $14.4 \%$ and have been fixed at $10.3 \%$ since 1993 .

${ }^{8}$ In total, many more models (103) enter than the number of models marketed before the beginning of the period (98-19=79.) But the exit of models is equally important (59), increasing after the two first years of the period, and tends to concentrate in some ages (from 4 to 8 years, say).

${ }^{9}$ Asian producers market a number of new models (28) that almost doubles the initial number accounted for them (15), while the entry of models by domestic producers (28) and non-Asian foreign producers (48) approximately matches their initial contribution of models ( 35 and 48 , respectively). 
${ }^{10}$ The logit model also provides a simple theoretical context in which the relative deterioration of an attribute of a good implies, in a Bertrand equilibrium context, a higher (absolute value) own-price demand elasticity and a fall in the market share of the good. The price set by the firm reacts in order to soften the direct share effect, but the firm finds it optimal not to offset it completely.

${ }^{11}$ A good source of discussion about this is Nevo (2000).

${ }^{12}$ We interpret their values as the realisations of the random variables conjugate to the extreme value errors that raise nested probabilities (Cardell, 1997).

${ }^{13}$ Car model demands are likely to entail important income effects, with consumers tending to cluster around model classes (segments) according to their income level, and average segment-specific marginal utilities are expected to reflect this heterogeneity. This preserves the useful linear form of equation (2) and will allow us to focus on the instrumental variables estimation choices (see the next section and appendix).

${ }^{14}$ Estimation of (3), using the constraint $\sum_{g}\left(\eta_{g}-\eta\right)=0$ to specify all the segment effects ( $\eta$ represents the average of these effects), gives coefficient estimates up to the scale factor $(1-\sigma)$ and mixes two unidentifiable components in the regression constant. Then, to estimate the $\sigma$ parameter, we construct estimates of the "inclusive values" $D_{g}=\sum_{j \in J_{g}} e^{\frac{u_{j}}{(1-\sigma)}}$ up to a multiplicative constant and perform the regression $\ln \hat{P}(g)-\ln \hat{P}(0)=c+(1-\sigma) \ln \hat{D}_{g}^{*}$. To avoid simultaneity biases, the "inclusive values" are constructed with the price values predicted by using the instruments.

${ }^{15}$ The most standard way of treating such a setting is to estimate the equation by taking first differences in order to difference out the individual correlated component, and to use lags of the endogenous variable to set valid moment restrictions (see, for example, Arellano and Honore (2001).) In our case, this is an undesirable alternative because $\mathrm{T}$ is short in relation to the pace of variation of attributes (many attributes change very little or not at all in the seven years). The differentiation of the attributes would eliminate crucial information contained in the levels equation and would exacerbate the variance of the disturbances.

${ }^{16}$ Instruments of this type were first proposed by Bhargava and Sargan (1983), and moment restrictions of this type have been studied in Arellano and Bover (1995). A recent application of moment restrictions that involve differenced instruments and level equations to treat persistent data is Blundell and Bond (2000).

17 The differences of a predetermined or endogenous variable with respect to its time mean introduce some correlation of the lags of the variable with the differenced error term that is likely to generate estimation biases in short panels (this is the type of bias analysed by Nickell, 1981.) However, this bias is likely to be negligible as $\mathrm{T}$ grows large enough.

${ }^{18}$ Collected from the population survey Encuesta de Población Activa. The monthly shares are multiplied by 12 in order to facilitate comparability to the elasticities obtained with yearly data. 
${ }^{19}$ We also experimented with sums of characteristics across own-firm products and rival firm products, in their totality and by segments. In general, they were found to be poorer instruments than the lagged price differences and tended to produce worse values for the Sargan statistic.

${ }^{20}$ GMM estimation of panel linear models is summarised in Arellano and Honore (2000).

${ }^{21}$ To estimate a robust inverse of $E\left(Z_{j}^{\prime} \bar{\xi}_{j} \bar{\xi}_{j}^{\prime} Z_{j}\right)$, we assume that $\bar{\xi}_{j} \bar{\xi}_{j}^{\prime \prime}=\Omega_{j}$ are matrices corresponding to conditional homoskedastic errors, and we obtain $\hat{\Omega}_{j}$ values using the Newey-West Bartlett kernel computations for the autocovariances of individual $\mathrm{j}$. Then we employ the usual "two-step" estimate $\left(\sum_{j} Z_{j}^{\prime} \hat{\Omega}_{j} Z_{j}\right)^{-1}$. We use 72 time observations as the maximum lag that we take into account in the Bartlett kernel.

22 For each time observation, we compute own-price elasticities of model $j$ as $\eta_{j}=\alpha_{g} p_{j}\left(1-s_{j}+\frac{\sigma}{1-\sigma}\left(1-s_{j g}\right)\right)$, where $s_{j g}$ is the share of model $j$ in segment $g$. 


\section{References}

Arellano, M., and B. Honoré (2001), "Panel data models: some recent developments," mimeo, Handbook of Econometrics, vol. 5, 3229-3296.

Arellano, M., and O. Bover (1995), "Another look at the instrumental-variable estimation of error components models," Journal of Econometrics, 68, 29-51.

Asplund, M., and R. Sandin (1999), "The survival of new products," Review of Industrial Organization, 15, 219-237.

Berry, S.T., (1994), "Estimating discrete-choice models of product differentiation," RAND Journal of Economics, 25, 242-262.

Berry, S.T., J. Levinsohn, and A. Pakes (1995), "Automobile prices in market equilibrium," Econometrica, 63, 841-890.

Berry, S.T., J. Levinsohn, and A. Pakes (1999), "Voluntary export restraints on automobiles: evaluating a trade policy," American Economic Review, 89, 400-430.

Berry, S.T., J. Levinsohn, and A. Pakes (2004), "Differentiated product demand systems from a combination of micro and macro data: the new car market". Journal of Political Economy, 112 (1), 68-105.

Bhargava, A., and J.D. Sargan (1983), "Estimating dynamic random effects models from panel data covering short time periods," Econometrica, 51, 1635-1659.

Blundell, R., and S. Bond (2000), "GMM estimation with persistent panel data: an application to production functions," Econometric Reviews, 19 (3), 321-340.

Bresnahan, T.F., (1987), "Competition and collusion in the American automobile industry: the 1955 price war," Journal of Industrial Economics, 35, 457-482.

Bresnahan, T.F., S. Stern and M. Trajtenberg (1997), "Market segmentation and the sources of rents from innovation: personal computers in the late 1980s," RAND Journal of Economics, 28, 17-44.

Cardell, N.S., (1997), "Variance components structures for the extreme-value and logistic distributions with applications to models of heterogeneity," Econometric Theory, 13 (2), 185-213.

Davis, P., (2006), "Spatial competition in retail markets: movie theatres", RAND Journal of Economics, forthcoming.

Feenstra, R., and J. Levinsohn (1995), "Estimating markups and market conduct with multidimensional product attributes," Review of Economic Studies, 62, 19-52.

Goeree, M., (2005), “Advertising in the US personal computer industry,” mimeo. 
Goldberg, P.K., (1995) "Product differentiation and oligopoly in international markets: the case of the U.S. automobile industry," Econometrica, 63, 891-951.

Goldberg, P.K., and F. Verboven (2001), "The evolution of price dispersion in the European car market," Review of Economic Studies, 68,811-848.

Greenstein, S.M., and J.B. Wade (1998), "The product life cycle in the commercial mainframe computer market, 1968-1982," RAND Journal of Economics, 29, 772789.

Kiefer, M., (1988), "Economic duration data and hazard functions," Journal of Economic Literature, 26, 646-679.

Klepper, S., (1996), "Entry, exit, growth and innovation over the product life cycle," American Economic Review, 86, 562-583.

Kwoka, J.E., (1996), "Altering the product life cycle of consumer durables: the case of minivans," Managerial and decision Economics, 17, 17-25.

McFadden, D., (1981), "Econometric models of probabilistic choice," in Structural Analysis of Discrete Data with Econometric Applications, C. Manski and D. McFadden eds., MIT Press.

Moral, M.J., (1999), “El mercado de automóviles en España: un modelo de oligopolio con producto diferenciado," Doctoral Thesis, Universidad Complutense de Madrid.

Nevo, A., (2000), “A practitioner's guide to estimation of random coefficients logit models of demand," Journal of Economics and Management Strategy, 9, 513-548.

Newey, W.K., and K.D. West (1987), "A simple, positive semi-definite, heteroskedasticity and autocorrelation consistent covariance matrix," Econometrica, 55, 703-708.

Nickell, S., (1981), "Biases in dynamic models with fixed effects," Econometrica, 49, 1417-1426.

Petrin, A., (2002), "Quantifying the benefits of new products: the case of minivan," Journal of Political Economy, 110, 4, 705-729.

Stavins, J., (1995), "Model entry and exit in a differentiated-product industry: The personal computer market," The Review of Economics and Statistics, 77, 571-584.

Verboven, F., (1996), "International price discrimination in the European car market," RAND Journal of Economics, 27, 240-268.

Wand, M.P., and M.C. Jones (1995), Kernel smoothing, Chapman \& Hall, London. 
Table 1: Degree of stability in model characteristics ${ }^{(1,2)}$

(No. and percentage of models with significant changes)

\begin{tabular}{ccccccc}
\hline \hline & \multicolumn{7}{c}{ Extent of the change } \\
\cline { 2 - 7 } Characteristics & \multicolumn{2}{c}{$2 \%$} & \multicolumn{2}{c}{$5 \%$} & $10 \%$ \\
\hline Stable: & & & & & \\
\multicolumn{1}{c}{ No. cyl } & 7 & $(3.85)$ & 7 & $(3.85)$ & 7 & $(3.85)$ \\
Length & 21 & $(11.54)$ & 7 & $(3.85)$ & 0 & $(0.00)$ \\
Width & 16 & $(8.79)$ & 5 & $(2.74)$ & 2 & $(1.10)$ \\
Varying: & & & & & & \\
Fiscalp & 42 & $(23.08)$ & 29 & $(15.93)$ & 15 & $(8.24)$ \\
CC & 44 & $(24.17)$ & 39 & $(21.43)$ & 29 & $(15.93)$ \\
Luggage & 47 & $(25.82)$ & 40 & $(21.97)$ & 29 & $(15.93)$ \\
Greatly varying: & & & & & & \\
HP & 77 & $(42.31)$ & 69 & $(37.91)$ & 55 & $(30.22)$ \\
RPM & 64 & $(35.16)$ & 49 & $(26.92)$ & 18 & $(9.89)$ \\
Maxspeed & 74 & $(40.66)$ & 38 & $(20.88)$ & 11 & $(6.04)$ \\
C90 & 83 & $(45.60)$ & 64 & $(35.16)$ & 39 & $(21.42)$ \\
C120 & 81 & $(44.50)$ & 59 & $(32.42)$ & 39 & $(21.42)$ \\
Ctown & 79 & $(43.41)$ & 62 & $(34.07)$ & 38 & $(20.88)$ \\
Weight & 73 & $(40.11)$ & 59 & $(32.42)$ & 25 & $(13.73)$ \\
\hline \hline
\end{tabular}

Notes:

1. Every column reports the number (percentage) of models that fail to pass the corresponding stability test. The test is passed if the characteristic does not change by more than, respectively, two, five or ten percent in a period of twelve months or less.

2. The definitions of the variables are in Table A.1. of the Data Appendix. 
Table 2: The Spanish car market in the 1990s

\begin{tabular}{ccrcccc}
\hline \hline Year & Registrations & Index $^{(1)}$ & No. of models & $\begin{array}{c}\text { Average monthly } \\
\text { sales by model }\end{array}$ & Price $^{(2)}$ & $\begin{array}{c}\text { Sales of } \\
\text { domestic } \\
\text { models }^{(3)}\end{array}$ \\
\hline 1990 & 971,466 & 109.7 & 98 & 851 & 1.976 & 82.0 \\
1991 & 878,594 & 99.2 & 106 & 712 & 1.948 & 80.0 \\
1992 & 973,414 & 109.9 & 117 & 700 & 1.876 & 81.3 \\
1993 & 737,938 & 83.3 & 120 & 520 & 1.928 & 80.2 \\
1994 & 901,754 & 101.8 & 124 & 616 & 1.925 & 78.7 \\
1995 & 829,797 & 93.7 & 127 & 556 & 1.982 & 77.2 \\
1996 & 906,444 & 102.3 & 133 & 580 & 1.986 & 75.2 \\
\hline \hline
\end{tabular}

Notes:

1. Index $=100$ at the time average of registrations.

2. Sales-weighted mean price, in millions of pesetas circa 1992. The weight for each monthly model observation is the average share of the model in the corresponding year.

3. Models sold by firms with domestic production, regardless of whether they are imported. 
Table 3: Entry, age distribution of models and exit.

\begin{tabular}{|c|c|c|c|c|c|c|c|c|}
\hline $\begin{array}{c}\text { Age } \\
\text { (in years) }\end{array}$ & 1990 & 1991 & 1992 & 1993 & 1994 & 1995 & 1996 & $\begin{array}{c}\text { Exit }^{(3)} \text { : until } \\
1995+1996\end{array}$ \\
\hline $\operatorname{age}^{(1,2)} \leq 1$ & 19 & 10 & 16 & 12 & 13 & 17 & 16 & \\
\hline $1<$ age $\leq 2$ & 3 & 19 & 10 & 16 & 12 & 13 & 17 & 1 \\
\hline $2<$ age $\leq 3$ & 7 & 3 & 19 & 10 & 16 & 11 & 13 & 4 \\
\hline $3<$ age $\leq 4$ & 18 & 7 & 3 & 18 & 10 & 14 & 10 & 5 \\
\hline $4<$ age $\leq 5$ & 5 & 18 & 6 & 3 & 18 & 7 & 13 & $6+2$ \\
\hline $5<$ age $\leq 6$ & 8 & 4 & 15 & 6 & 3 & 16 & 7 & $3+1$ \\
\hline $6<$ age $\leq 7$ & 6 & 8 & 4 & 13 & 6 & 3 & 15 & $5+3$ \\
\hline $7<$ age $\leq 8$ & 5 & 6 & 8 & 3 & 12 & 4 & 2 & 7 \\
\hline $8<$ age $\leq 9$ & 6 & 4 & 6 & 6 & 2 & 10 & 3 & 8 \\
\hline $9<$ age $\leq 10$ & 4 & 6 & 4 & 4 & 3 & 2 & 7 & +1 \\
\hline $10<$ age $\leq 11$ & 4 & 4 & 6 & 4 & 4 & 3 & 2 & 4 \\
\hline $11<$ age $\leq 12$ & 0 & 4 & 4 & 5 & 2 & 3 & 3 & 2 \\
\hline $12<$ age $\leq 13$ & 1 & 0 & 3 & 3 & 5 & 2 & 3 & 2 \\
\hline $13<$ age $\leq 14$ & 4 & 1 & 0 & 3 & 2 & 5 & 1 & $1+1$ \\
\hline $14<$ age $\leq 15$ & 3 & 4 & 1 & 0 & 3 & 2 & 4 & +1 \\
\hline $15<$ age $\leq 16$ & 5 & 3 & 4 & 1 & 0 & 3 & 2 & \\
\hline $16<$ age $\leq 17$ & & 5 & 3 & 4 & 1 & 0 & 3 & \\
\hline $17<$ age $\leq 18$ & & & 5 & 3 & 4 & 1 & 0 & \\
\hline $18<$ age $\leq 19$ & & & & 5 & 3 & 4 & 1 & 1 \\
\hline $19<$ age $\leq 20$ & & & & & 4 & 3 & 4 & 1 \\
\hline $20<$ age $\leq 21$ & & & & & & 3 & 3 & \\
\hline $21<$ age $\leq 22$ & & & & & & & 3 & \\
\hline \multirow[t]{2}{*}{ No. of models } & 98 & 106 & 117 & 119 & 124 & 127 & 133 & \\
\hline & & & & & & & \multicolumn{2}{|r|}{ Totals: } \\
\hline Entry & $19^{(4)}$ & 10 & 16 & 12 & 13 & 17 & 16 & 103 \\
\hline Exit & 2 & 5 & 10 & 9 & 14 & 10 & 9 & 59 \\
\hline
\end{tabular}

Notes:

1. The first category represents a number of months equal to or less than 12 .

2. Each entry is the number of models of a given age observed during the year.

3. Exits are equal to the difference between the number of models belonging to the interval of $s$ years at time $t$ and the number of models in the interval $s+1$ years at time $t+1$. Exits during 1996 cannot be observed in this way and we report them separately.

4. Includes the entry of 8 models in January 1990. Four of them stay until the end of the sample and the other four exit before December 1996. 
Table 4: Entry and exit of models by firms ${ }^{(1)}$.

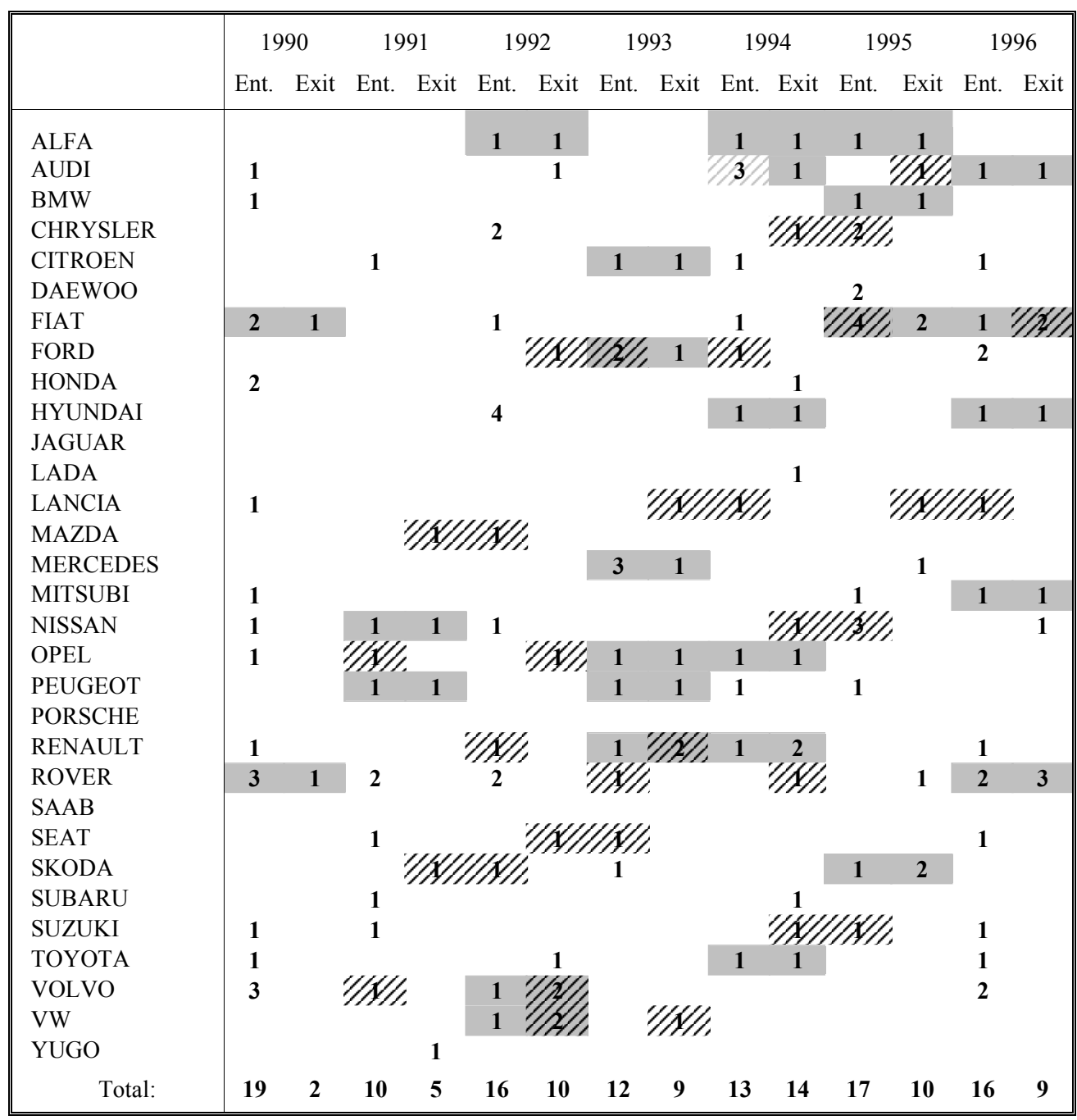

Note:

1. Shaded areas highlight entry-exit pairs separated at most by two years. 
Table 5: Logit demand for car models with age effects

\begin{tabular}{|c|c|c|c|}
\hline \multicolumn{2}{|c|}{$\begin{array}{l}\text { Dependent variable: } \ln s_{j}-\ln s_{0} \\
\text { Sample period }{ }^{2}: \text { I-1990 to XII-1996 }\end{array}$} & \multicolumn{2}{|c|}{$\begin{array}{l}\text { Estimation method: } \mathrm{GMM}^{1} \\
\text { Observations }^{2}: 7,122 \text { No. of models } \\
2\end{array}$} \\
\hline \multicolumn{2}{|c|}{ Variable } & Coefficient & t-ratio $^{3}$ \\
\hline \multicolumn{2}{|l|}{ Constant } & -15.840 & -6.70 \\
\hline \multicolumn{2}{|l|}{$\mathrm{CC} /$ Weight } & 1.332 & 2.46 \\
\hline \multicolumn{2}{|l|}{ Maxspeed } & 0.034 & 2.92 \\
\hline \multicolumn{2}{|l|}{$\mathrm{Km} / 1$} & 0.071 & 1.61 \\
\hline \multicolumn{2}{|l|}{ Size } & 0.651 & 3.42 \\
\hline \multirow[t]{3}{*}{ Segment effects ${ }^{4}:$} & Small domestic & 5.152 & 3.49 \\
\hline & Intermediate & -2.831 & -1.97 \\
\hline & Luxury & -4.969 & -3.57 \\
\hline \multirow[t]{5}{*}{ Price $x$ segment: } & Small & -4.916 & -2.67 \\
\hline & Compact & -3.374 & -2.65 \\
\hline & Intermediate & -0.931 & -3.53 \\
\hline & Luxury & -0.593 & -2.97 \\
\hline & Minivan & -2.575 & -3.12 \\
\hline \multirow[t]{3}{*}{ Age polynomial ${ }^{5}$ : } & Age & -4.816 & -2.27 \\
\hline & age $^{\wedge}$ & 3.884 & 1.93 \\
\hline & $\operatorname{age}^{\wedge} 3$ & -0.905 & -1.62 \\
\hline \multirow[t]{12}{*}{ Price $x$ age $^{6}:$} & $1<$ age $\leq 2$ & -0.381 & -3.37 \\
\hline & $2<$ age $\leq 3$ & -0.135 & -2.01 \\
\hline & $4<$ age $\leq 5$ & -0.015 & -0.20 \\
\hline & $5<$ age $\leq 6$ & 0.023 & 0.24 \\
\hline & $6<$ age $\leq 7$ & -0.085 & -0.85 \\
\hline & $7<$ age $\leq 8$ & -0.037 & -0.32 \\
\hline & $8<$ age $\leq 9$ & 0.081 & 0.64 \\
\hline & $9<$ age $\leq 10$ & 0.161 & 1.27 \\
\hline & $10<$ age $\leq 11$ & -0.052 & -0.40 \\
\hline & $11<$ age $\leq 12$ & -0.041 & -0.29 \\
\hline & $12<$ age $\leq 13$ & 0.099 & 0.66 \\
\hline & $21<$ age $\leq 22$ & 0.100 & 0.51 \\
\hline \multicolumn{2}{|l|}{ Seasonal dummies } & Yes & \\
\hline \multicolumn{2}{|l|}{ Time dummies } & Yes & \\
\hline \multicolumn{2}{|c|}{$\sigma$ estimate } & 0.842 & 7.51 \\
\hline \multirow{2}{*}{\multicolumn{2}{|c|}{$\begin{array}{l}\text { Sargan test }^{7}(25 \text { degrees of freedom }) \\
\text { Serial autocorrelation } \text { statistic }^{8}(\mathrm{~m} 12)\end{array}$}} & 35.86 & \\
\hline & & 5.921 & \\
\hline
\end{tabular}

Notes:

1. Instruments: differences of prices with respect to their time mean lagged 6 and 12 months (interacted with the segment dummies), 20 age dummies, interactions of the age dummies with the price differences lagged 12 months.

2. Instruments lagged 12 months imply that models with 12 or fewer observations must be removed.

3. Standard errors are robust to heteroskedasticity and serial correlation.

4. Small-mini, compact and minivan dummy coefficients constrained to be equal to the average effect.

5. Age in months.

6. Age intervals in years. We exclude the category $3<$ age $\leq 4$. Intervals from 9 to 21 years not shown.

7. Two-step statistic.

8. Constructed as Arellano-Bond m-statistics. 
Table 6:

A sample of own and cross-price elasticities ${ }^{1}$

(x100 cross-price cross-segment elasticities ${ }^{2}$ )

\begin{tabular}{|c|c|c|c|c|c|c|c|c|c|c|c|c|c|c|c|}
\hline & \multicolumn{3}{|c|}{ Small mini } & \multicolumn{3}{|c|}{ Small } & \multicolumn{3}{|c|}{ Compact } & \multicolumn{3}{|c|}{ Intermediate } & \multicolumn{3}{|c|}{ Luxury } \\
\hline & $\begin{array}{l}\text { Fiat } \\
\text { Uno }\end{array}$ & $\begin{array}{c}\text { Seat } \\
\text { Marbella }\end{array}$ & $\begin{array}{c}\text { Rover } \\
114\end{array}$ & $\begin{array}{l}\text { Ford } \\
\text { Fiesta }\end{array}$ & $\begin{array}{l}\text { Seat } \\
\text { Ibiza }\end{array}$ & $\begin{array}{c}\text { Peugeot } \\
205\end{array}$ & $\begin{array}{l}\text { Ford } \\
\text { Escort }\end{array}$ & $\begin{array}{l}\text { Opel } \\
\text { Astra }\end{array}$ & $\begin{array}{l}\text { VW } \\
\text { Golf }\end{array}$ & $\begin{array}{l}\text { Citroen } \\
\text { Xantia }\end{array}$ & $\begin{array}{c}\text { Ford } \\
\text { Mondeo }\end{array}$ & $\begin{array}{c}\text { Opel } \\
\text { Vectra }\end{array}$ & $\begin{array}{c}\text { BMW } \\
525\end{array}$ & $\begin{array}{l}\text { Mercedes } \\
300\end{array}$ & $\begin{array}{c}\text { Volvo } \\
850\end{array}$ \\
\hline Fiat Uno & -4.033 & 1.185 & 0.169 & 0.421 & 0.390 & 0.203 & 0.279 & 0.420 & 0.278 & 0.019 & 0.024 & 0.021 & 0.007 & 0.017 & 0.014 \\
\hline Seat Marbella & 1.396 & -3.235 & 0.144 & 0.417 & 0.399 & 0.192 & 0.278 & 0.394 & 0.277 & 0.037 & 0.042 & 0.034 & 0.007 & 0.017 & 0.012 \\
\hline Rover 114 & 1.215 & 1.085 & -6.227 & 0.410 & 0.381 & 0.167 & 0.282 & 0.400 & 0.266 & 0.014 & 0.017 & 0.038 & 0.007 & 0.016 & 0.013 \\
\hline Ford Fiesta & 0.081 & 0.060 & 0.010 & -5.776 & 0.913 & 0.455 & 0.280 & 0.405 & 0.267 & 0.010 & 0.012 & 0.019 & 0.007 & 0.016 & 0.013 \\
\hline Seat Ibiza & 0.081 & 0.060 & 0.010 & 0.949 & -5.820 & 0.455 & 0.280 & 0.404 & 0.268 & 0.010 & 0.012 & 0.019 & 0.007 & 0.017 & 0.013 \\
\hline Peugeot 205 & 0.081 & 0.059 & 0.010 & 0.949 & 0.913 & -5.899 & 0.280 & 0.400 & 0.269 & 0.009 & 0.011 & 0.021 & 0.007 & 0.017 & 0.013 \\
\hline Ford Escort & 0.080 & 0.058 & 0.010 & 0.415 & 0.399 & 0.193 & -5.294 & 0.909 & 0.616 & 0.207 & 0.231 & 0.139 & 0.009 & 0.018 & 0.006 \\
\hline Opel Astra & 0.044 & 0.049 & 0.007 & 0.387 & 0.389 & 0.140 & 0.721 & -5.764 & 0.586 & 0.210 & 0.234 & 0.081 & 0.009 & 0.016 & 0.005 \\
\hline VW Golf & 0.080 & 0.059 & 0.010 & 0.414 & 0.399 & 0.193 & 0.740 & 0.909 & -7.030 & 0.254 & 0.285 & 0.155 & 0.010 & 0.018 & 0.004 \\
\hline Citroen Xantia & 0.017 & 0.045 & 0.005 & 0.417 & 0.430 & 0.140 & 0.297 & 0.361 & 0.256 & -2.449 & 0.643 & 0.440 & 0.011 & 0.013 & 0.000 \\
\hline Ford Mondeo & 0.019 & 0.044 & 0.005 & 0.414 & 0.424 & 0.139 & 0.294 & 0.359 & 0.255 & 0.580 & -2.410 & 0.438 & 0.011 & 0.014 & 0.000 \\
\hline Opel Vectra & 0.076 & 0.051 & 0.009 & 0.422 & 0.402 & 0.189 & 0.280 & 0.403 & 0.267 & 0.581 & 0.651 & -2.477 & 0.017 & 0.023 & 0.000 \\
\hline BMW 525 & 0.074 & 0.046 & 0.008 & 0.425 & 0.403 & 0.186 & 0.284 & 0.426 & 0.253 & 1.567 & 1.748 & 1.021 & -2.631 & 0.545 & 0.433 \\
\hline Mercedes 300 & 0.073 & 0.044 & 0.008 & 0.427 & 0.404 & 0.185 & 0.286 & 0.440 & 0.243 & 2.012 & 2.239 & 1.201 & 0.321 & -3.258 & 0.433 \\
\hline Volvo 850 & 0.032 & 0.040 & 0.006 & 0.403 & 0.407 & 0.134 & 0.273 & 0.382 & 0.248 & 1.206 & 1.349 & 0.301 & 0.350 & 0.515 & -2.797 \\
\hline
\end{tabular}

Notes:

1. Cell entries $j, k$, where $\mathrm{j}$ is row and $\mathrm{k}$ column, give the percent change in sales (or market share) of model $j$ with a one percent change in price of model $k$.

2. Cross- price elasticities between models of different segments are multiplied by 100 (the sample includes an average of 110 models/year). 
Table 7: Age effects and own-price elasticities.

\begin{tabular}{|c|c|c|c|c|c|c|c|c|c|c|c|c|c|c|c|}
\hline \multirow[b]{3}{*}{ Age $^{1}$} & \multirow[b]{3}{*}{$\begin{array}{l}\text { Survival } \\
\text { Function }^{2}\end{array}$} & \multirow[b]{3}{*}{$\begin{array}{l}\text { Mean } \\
\text { utility }^{3}\end{array}$} & \multicolumn{13}{|c|}{ Average elasticities by age, segment and interval of survival ${ }^{4}$} \\
\hline & & & Total & Total & $\begin{array}{l}\text { Small } \\
\text { mini }\end{array}$ & $\begin{array}{l}\text { Small } \\
\text { mini }\end{array}$ & $\begin{array}{l}\text { Small } \\
\text { dom. }\end{array}$ & $\begin{array}{l}\text { Small } \\
\text { dom. }\end{array}$ & Compact & Compact & Interm. & Interm. & Luxury & Luxury & Minivan \\
\hline & & & $1-6^{5}$ & $7-12^{5}$ & $1-6$ & $7-12$ & $1-6$ & $7-12$ & $1-6$ & $7-12$ & $1-6$ & $7-12$ & $1-6$ & $7-12$ & $1-6$ \\
\hline 1 & 1.00 & 1.00 & 4.52 & & 5.64 & & 6.56 & & 6.73 & & 3.27 & & 3.32 & & 6.51 \\
\hline 2 & 0.99 & 1.29 & 3.94 & 2.41 & 5.31 & & 6.07 & & 6.25 & & 2.77 & 2.47 & 2.50 & 2.34 & 5.97 \\
\hline 3 & 0.96 & 1.34 & 3.78 & 3.21 & 5.19 & & 6.43 & & 6.34 & 5.57 & 2.45 & 2.22 & 1.94 & 1.84 & 5.15 \\
\hline 4 & 0.92 & 1.09 & 3.92 & 3.69 & 5.73 & 6.10 & 6.99 & 5.33 & 6.50 & 7.01 & 2.31 & 2.38 & 2.37 & 2.11 & 5.58 \\
\hline 5 & 0.81 & 0.96 & 4.13 & 3.50 & 6.17 & 5.60 & 7.09 & 5.10 & 6.32 & 6.40 & 2.21 & 2.41 & 2.28 & 1.98 & \\
\hline 6 & 0.73 & 0.89 & 4.26 & 3.81 & 6.21 & 6.00 & 7.18 & 6.05 & 6.85 & 6.40 & 2.32 & 2.83 & 2.31 & 2.71 & \\
\hline 7 & 0.65 & 0.87 & & 3.81 & & 6.20 & & 6.11 & & 6.42 & & 2.48 & & 2.52 & \\
\hline 8 & 0.56 & 0.88 & & 3.78 & & 6.38 & & 5.70 & & 7.54 & & 2.33 & & 2.07 & \\
\hline 9 & 0.48 & 0.93 & & 3.77 & & & & 5.49 & & 6.78 & & 2.40 & & 1.74 & \\
\hline 10 & 0.39 & 0.99 & & 4.55 & & & & 6.00 & & 6.07 & & 3.30 & & 2.98 & \\
\hline 11 & 0.37 & 1.08 & & 4.99 & & & & 6.18 & & 6.38 & & 3.60 & & 3.08 & \\
\hline 12 & 0.29 & 1.18 & & 5.31 & & & & 6.12 & & & & 3.73 & & & \\
\hline
\end{tabular}

Notes:

1. Age $x$ is a shorthand for the numbers of months comprised between $x$ and $x+1$ years.

2. Age effects are conditional on survival.

3. Ratio of mean utility at the specified age to age 1, keeping everything but age constant. The significant marginal utility effects are computed at the sample median price (2.5).

4. Averages of the elasticities observed at the indicated age and segment for models belonging to the specified survival interval.

5. Intervals of survival: 1-6, cars which survive from 1 to 7 years; 7-12, cars which survive from 7 to 13 years. 
Table A.1: Variables

\begin{tabular}{ll}
\hline \hline Price & $\begin{array}{l}\text { Market price in millions of pesetas circa 1992. It } \\
\text { includes indirect tax, transport and registration cost. }\end{array}$ \\
\hline CC & Cubic centimetres \\
\hline HP & Horsepower \\
\hline Fiscalp & $\begin{array}{l}\text { Fiscal power, fiscal horses according to Spanish } \\
\text { legislation. }\end{array}$ \\
\hline RPM & Revolutions per minute \\
\hline Maxspeed & Maximum speed (in kph) \\
\hline C90 & $\begin{array}{l}\text { Consumption (in litres) to cover } 100 \mathrm{~km} \mathrm{at} \mathrm{a} \\
\text { constant speed of } 90 \mathrm{kph} .\end{array}$ \\
\hline Ctown & $\begin{array}{l}\text { Consumption (in litres) to cover } 100 \mathrm{~km} \mathrm{at} \mathrm{a} \\
\text { constant speed of } 120 \mathrm{kph} .\end{array}$ \\
\hline Length & $\begin{array}{l}\text { Consumption (in litres) to cover } 100 \mathrm{~km} \text { in town at } \\
\text { a constant speed of } 90 \mathrm{kph} .\end{array}$ \\
\hline Weight & Length in cm \\
\hline Width & Weight in kg \\
\hline Luggage & Width in cm \\
\hline No. cyl & Luggage capacity in $\mathrm{cm}^{3}$ \\
\hline Age & Number of cylinders \\
\hline \hline
\end{tabular}


Figure 1: Conditional expectation function of shares*.

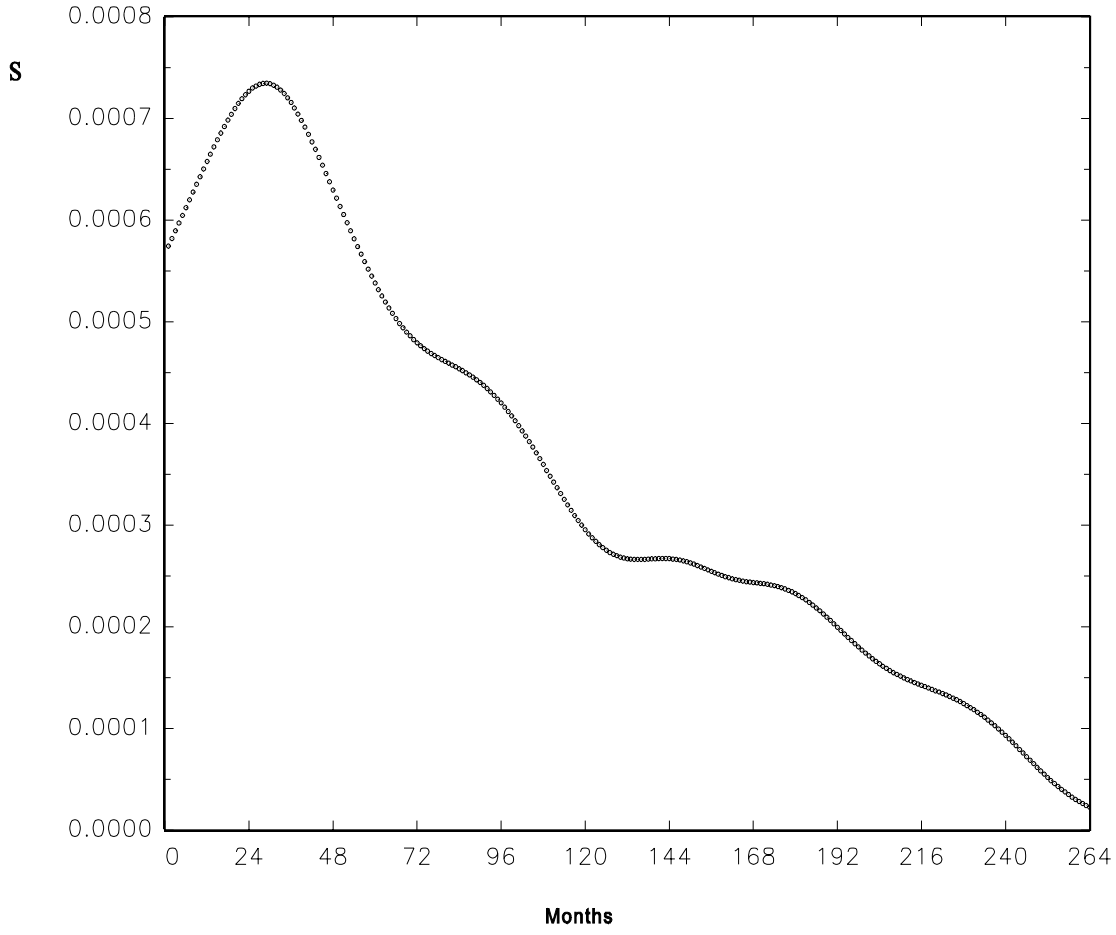

Note:

Shares are computed by taking the current number of households as the market size. 
Figure 2.a: Survival function of models.

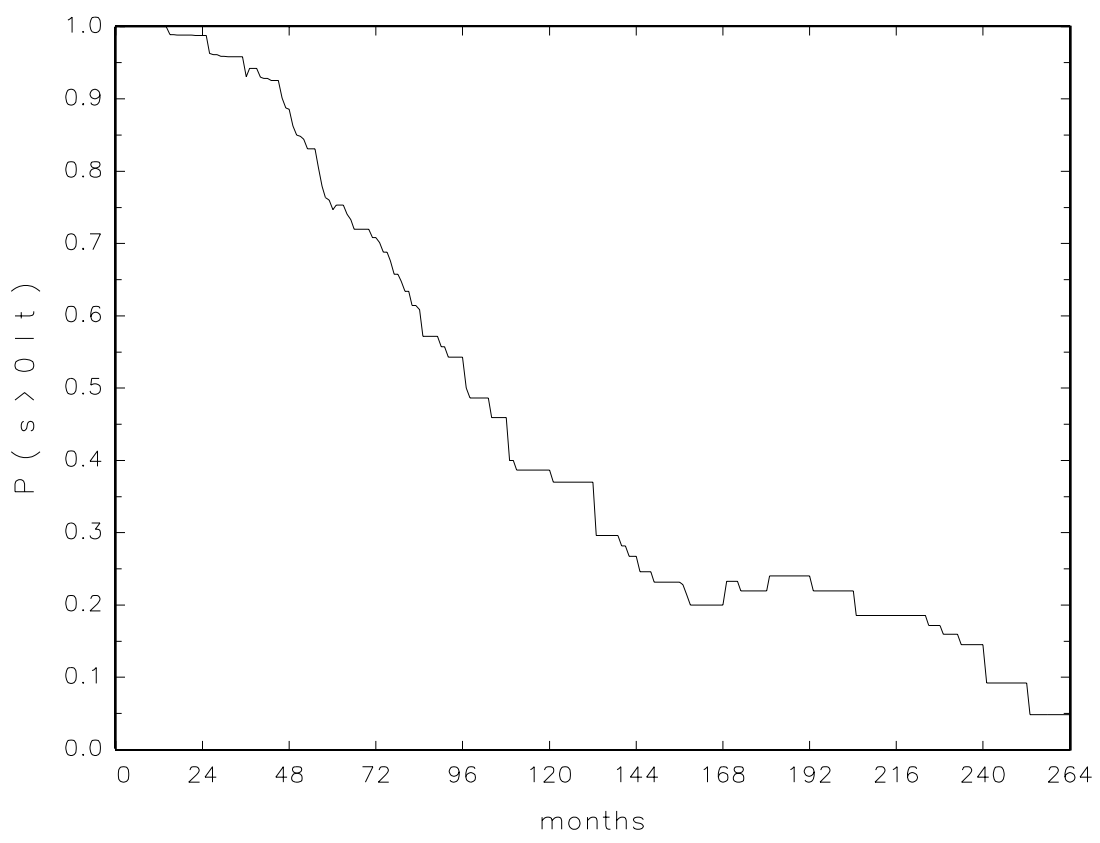

Figure 2.b: Expectation of market share conditional on age and survival

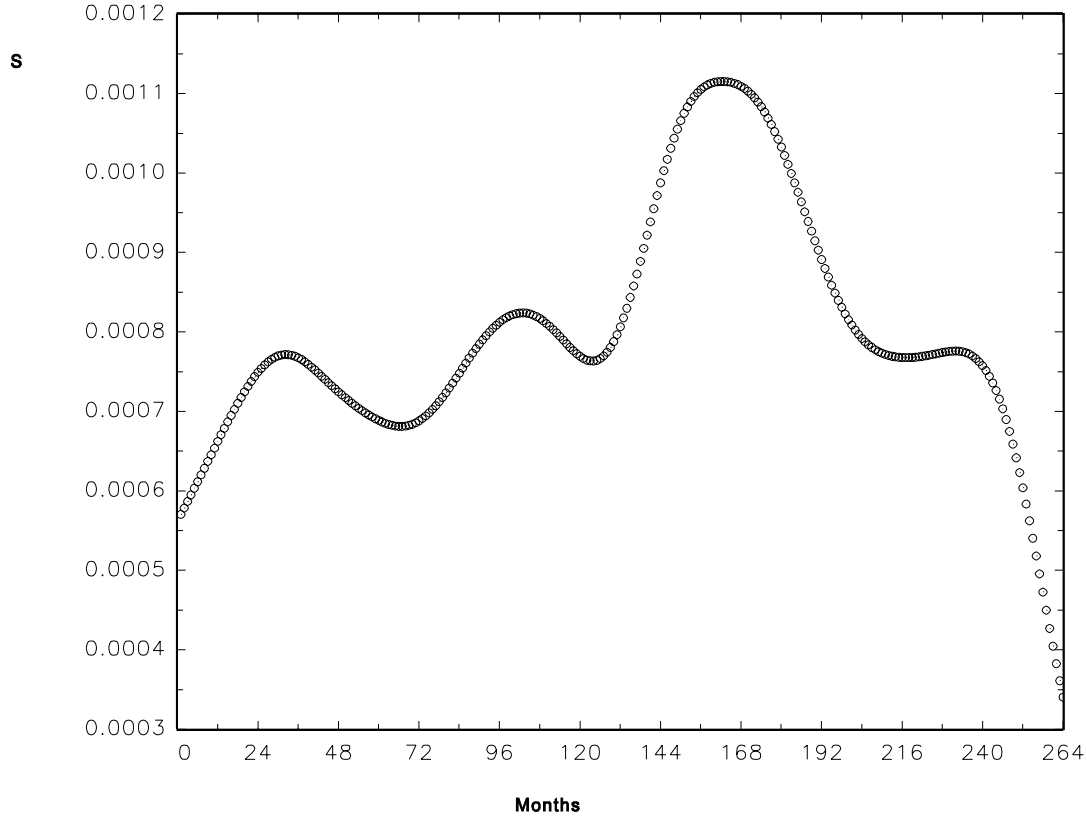


Figure 3a: Conditional expectation functions of shares of domestic models.
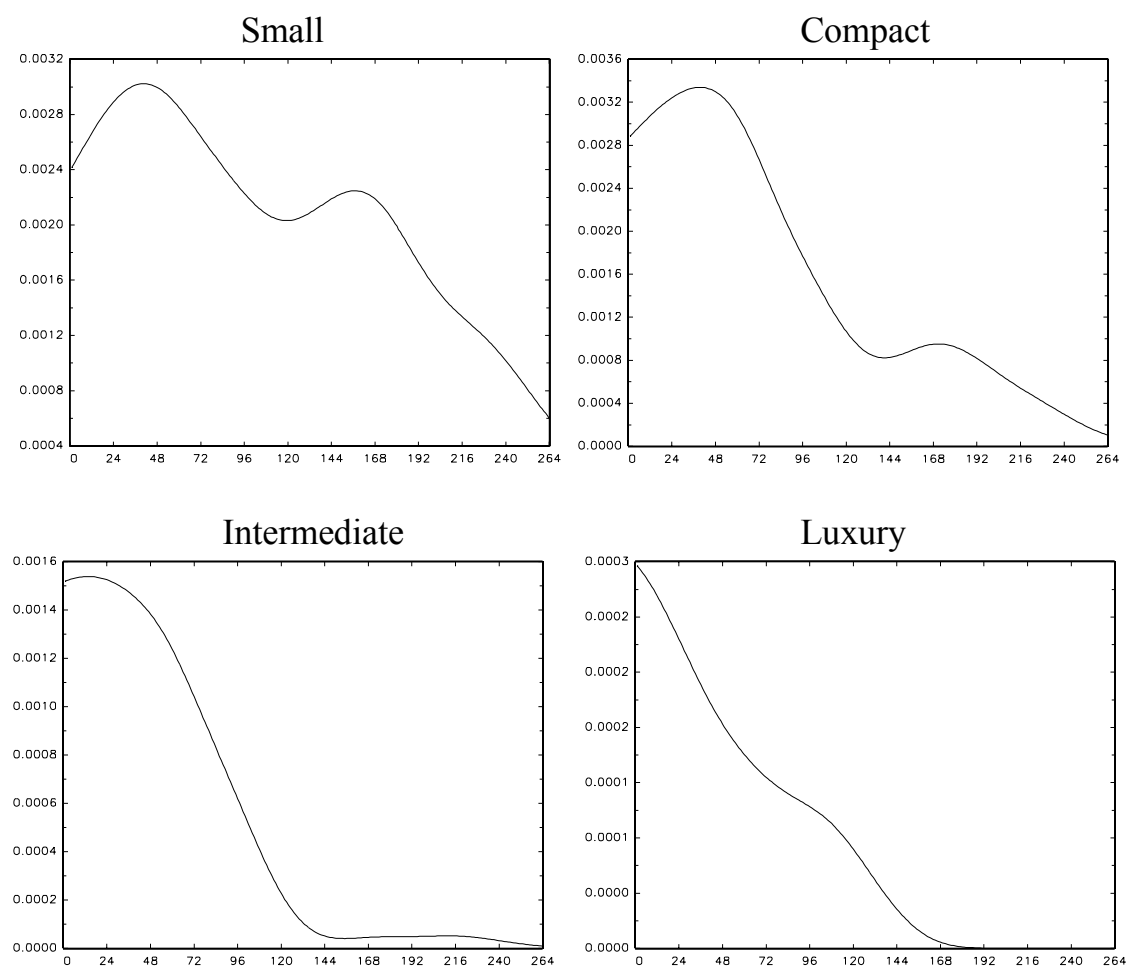

Figure 3.b: Conditional expectation functions of shares of foreign models.
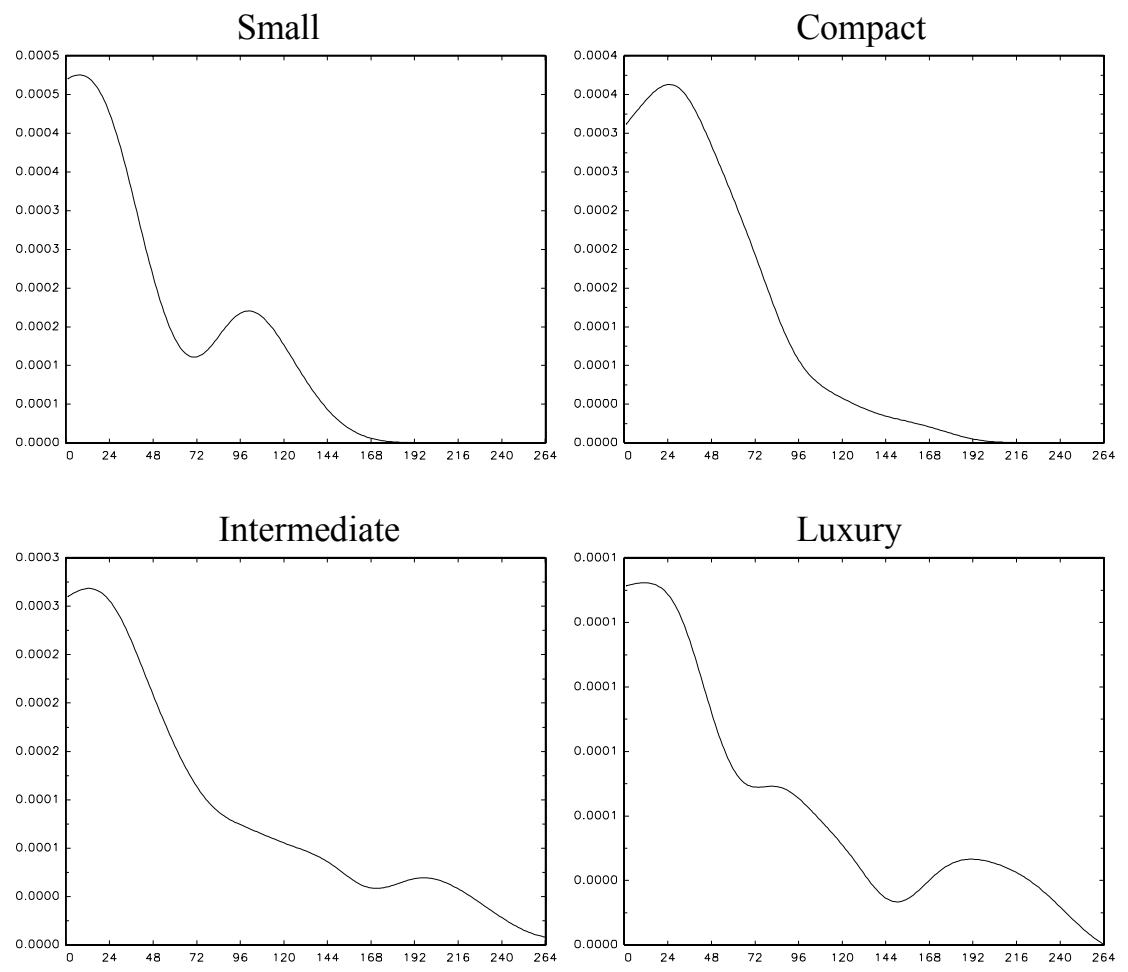
Figure A1: Frequencies of the non-censured observations.

(19,528 observations)

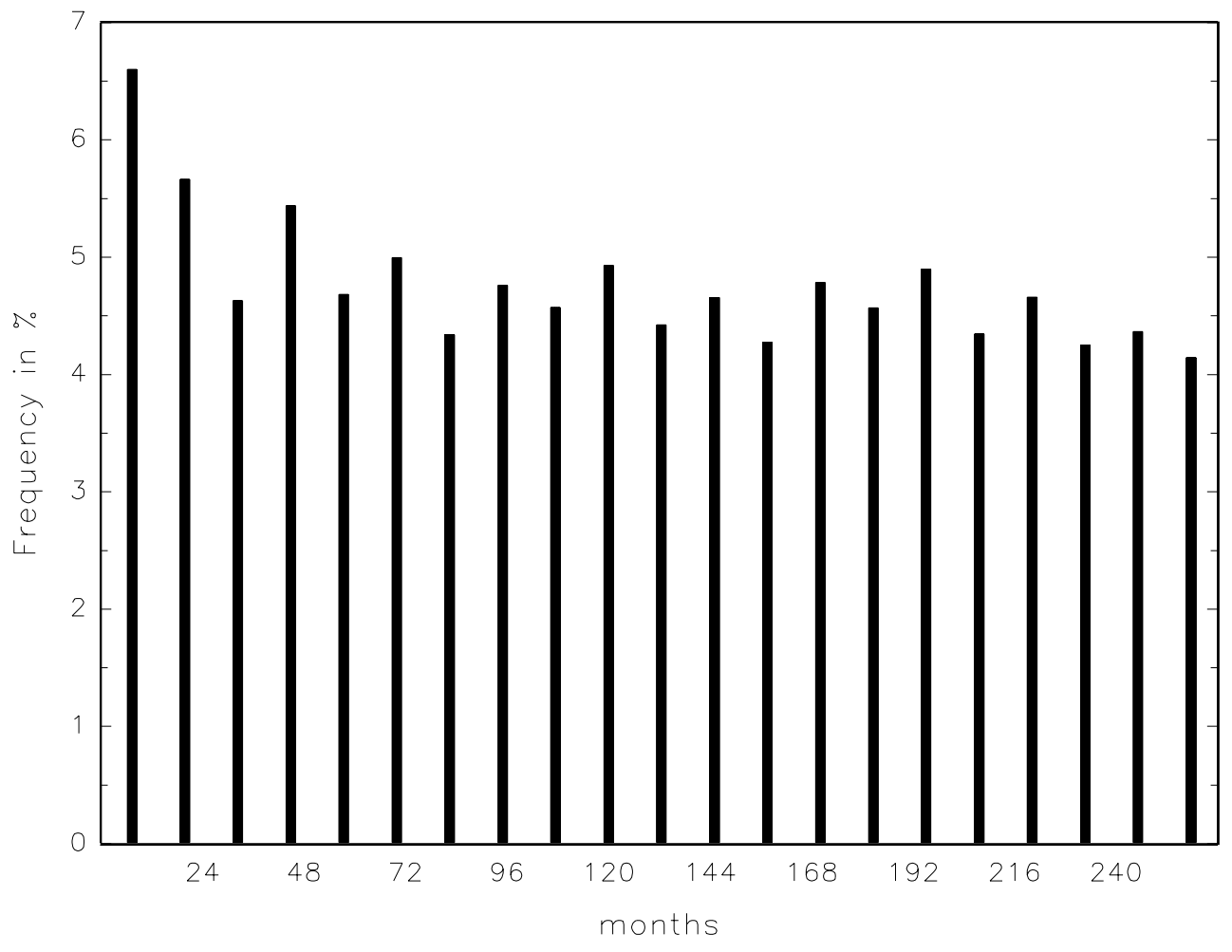

